\title{
A organização do conhecimento no domínio da Ciência da Informação: o mapa conceitual e terminológico como instrumento referencial para o ensino e a pesquisa
}

\author{
Knowledge organization in the field of Information Science: conceptual and terminological \\ maps as tools for teaching and research
}

Vânia Mara Alves Lima

Doutora em Ciências da Comunicação pela Escola de Comunicações e Artes da Universidade de São Paulo ECA/USP. Docente e Coordenadora do curso de Biblioteconomia da ECA/USP.

E-mail: vamal@usp.br

\section{Resumo}

Este trabalho apresenta alguns referenciais teóricos e metodológicos na tentativa de nortear a elaboração de um mapa conceitual e terminológico que referencie o ensino e a pesquisa no domínio da Ciência da Informação, além de referenciar os processos de representação e recuperação da informação em bibliotecas, arquivos, museus e centros de documentação.

Palavras-chave: Mapa conceitual. Terminologia. Ciência da Informação.

\begin{abstract}
This works investigates some methodological framework in order to show a terminological and concept map to researches in Information Science. It is also highlighted the representation and the information retrieval for Library systems, Museums and Archives Institutions.
\end{abstract}

Keywords: Conceptual map. Terminology. Information Science.

\section{Introdução}

Atualmente, reconhece-se a necessidade de que as novas gerações devem ser preparadas não apenas para absorver, mas, sobretudo, para produzir novos conhecimentos. A crescente interdisciplinaridade entre as mais diversas áreas do saber demanda novas perspectivas educacionais que contribuam para o desenvolvimento dos diferentes segmentos sociais, tanto do ponto de vista cultural quanto econômico.

Não se concebe o surgimento e o desenvolvimento de nenhuma ciência ou disciplina que não esteja sobre uma plataforma de conceitos organizados em um sistema, pois os conceitos existem desde que o homem teve a capacidade de abstrair, ou seja, de tomar da realidade elementos significativos e intrínsecos de cada objeto ou fenômeno, e de associar ou dissociar esses elementos em função de semelhanças ou diferenças. Assim, sem a apropriação 
dos conceitos, ou seja, sem a compreensão do significado de cada conceito e sua relação com os demais conceitos que constituem uma ciência, não há produção de novos conhecimentos e por esse motivo impõe-se a elaboração de instrumentos que permitam determinar a estrutura conceitual dos domínios no ensino e na pesquisa (BARITÉ ROQUETA, 2001).

O conhecimento científico exige um olhar transversal, isso porque atualmente passa de um esquema hierárquico em forma de árvore, onde as novas disciplinas se ligam à disciplina fundamental por um tronco comum, para um esquema em forma de rede neural, onde as relações são múltiplas e irregulares (POMBO, 2010)

Por esse motivo, é necessária uma precisão terminológica no tratamento das questões referentes à integração das áreas que constituem a rede da Ciência da Informação, que na perspectiva nesse trabalho são: a Biblioteconomia e Documentação, a Arquivologia e a Museologia.

Portanto, é preciso identificar referenciais teóricos e metodológicos que permitam operacionalizar a construção de uma estrutura conceitual significante, isto é, um mapa conceitual e terminológico, que referencie o ensino e a pesquisa no domínio da Ciência da Informação. Outra aplicação deste mapa conceitual terminológico seria também referenciar os processos de representação e recuperação da informação nos sistemas de informação como bibliotecas, arquivos, museus e centros de documentação.

Em primeiro lugar, apresentamos as relações entre a Biblioteconomia e Documentação, a Arquivologia e a Museologia no domínio da Ciência da Informação. Em segundo lugar, apresentamos a Terminologia, mais especificamente a Teoria Comunicativa da Terminologia, enquanto referencial teórico para a estruturação deste mapa conceitual e terminológico, na medida em que ao definir critérios para elencar conceitos, suas definições e suas denominações dentro de um determinado domínio, estrutura o conhecimento produzido e possibilita a sua disseminação.

Em segundo lugar, identificamos as ontologias e os topic maps, enquanto referencial metodológico, na medida em que suas características podem ser compiladas para a estruturação de um mapa conceitual terminológico da Ciência da Informação devido à automatização dos processos de armazenamento, representação e recuperação da informação, sem os quais não se completa o ciclo da disseminação da produção científica. 
Por ultimo discutimos a elaboração do mapa conceitual e terminológico da Ciência da Informação, a partir do estabelecimento do signo fundamental do domínio e de suas categorias, ou seja, o conceito a partir do qual todos os demais são compreendidos e que garante a manutenção do projeto na trilha terminológica, no caso o conceito de informação.

\section{A Biblioteconomia e Documentação, a Arquivologia e a Museologia no domínio da Ciência da Informação}

Conforme Araújo (2010) na Biblioteconomia existe uma vasta produção teórica sobre a atividade profissional do bibliotecário e sobre a instituição biblioteca, além de seu relacionamento com a Ciência da Informação, mas o mesmo não ocorre na Arquivologia e na Museologia. Na Arquivologia a produção teórica se concentra sobre a profissão e a instituição arquivo a partir de reflexões realizadas nos campos da história e da administração e na Museologia as reflexões teóricas concentram-se na arte, história, educação e ciência e suas relações com a instituição museu e o fazer museológico.

Segundo o autor a escassa literatura que reúne a Museologia, a Biblioteconomia e a Arquivologia geralmente está mais relacionada a discussões sobre memória e o patrimônio cultural. Por esse motivo, ele defende a necessidade de se construir uma Ciência da Informação que contemple os diferentes fazeres e as diferentes instituições de informação e se beneficie da experiência milenar das técnicas e reflexões desenvolvidas tanto na Biblioteconomia, quanto na Arquivologia e na Museologia (ARAÚJO, 2010).

Segundo Araújo (2010) construção do domínio da Ciência da Informação passa pelo levantamento dos pontos em comum entre as três áreas que incluem principalmente a reflexão sobre questões como a administração das instituições, a preservação do acervo e a utilização de algum critério de organização, mas, devem-se levar em conta as especificidades de cada uma delas destacando-se:

- no caso da Biblioteconomia, a relação entre biblioteca e práticas de leitura, história do livro, papel da biblioteca na educação e na divulgação do conhecimento;

- no caso da Arquivologia as relações entre os arquivos e a administração pública das cidades, a comprovação de atos jurídicos e, também, a dimensão histórica das sociedades; 
- no caso da Museologia, sua relação com a preservação e a exposição de coleções de obras de arte (ou mesmo de objetos do mundo natural) e, ainda, uma dimensão relacionada à preservação do patrimônio histórico, de um lado, e, de outro, o aspecto educacional da instituição museu.

Para Smit (2002), a Biblioteconomia, a Arquivologia e a Museologia são ciências documentais que não nasceram separadas, mas se afastaram ao longo do tempo devido à disputa entre dois pontos de vista diferentes, o primeiro baseado nas práticas profissionais e ancorado no paradigma do acervo e o segundo voltado para a função social de instituições que coletam, estocam e disponibilizam informações. De acordo com a autora, o estatuto científico da Ciência da Informação somente poderá ser confirmado quando for abandonada a visão pragmática das práticas profissionais e quando se dispuser de teorias e princípios gerais, comuns às três áreas.

$\mathrm{Na}$ visão de Silva (2002), o paradigma patrimonialista que norteava tanto a Biblioteconomia, quanto a Arquivologia e a Museologia, a partir do século XX e das inovações tecnológicas, é substituído pelo paradigma da informação e, assim essas três áreas fazem parte integrante de um "corpus científico unificado pelo mesmo objeto", objeto esse que seria a informação, enquanto fenômeno e enquanto processo. É interessante destacar que o desenvolvimento e a utilização das novas tecnologias, para o armazenamento e a recuperação da informação, praticamente impõe a essas áreas o usuário, como foco principal, e a partir daí, segundo o autor, se inicia um movimento de convergência das discussões em direção ao que tem sido denominado como Ciência da Informação.

De acordo com Galvão e Borges (2000) o conceito científico de informação surge na metade do século XX, a partir de alguns trabalhos teóricos, como o texto As we may think? (BUSH, 1945), mas é no texto de Borko, Information Science: what is it? (1968) que se encontra uma definição da área como "ciência interdisciplinar derivada e relacionada à Matemática, à Lógica, à Linguística, à Psicologia, à Informática, à Pesquisa, às Artes Gráficas, às Comunicações, à Biblioteconomia, à Administração e a outras áreas afins". Além disso, Borko enumera como campos de pesquisa para a Ciência da Informação a demanda da informação, a produção e reprodução de documentos, a análise linguística, a tradução, as linguagens documentárias, a análise e projeto de sistemas, padrões de reconhecimento de imagens e de voz e os sistemas especialistas. 
Ainda conforme Galvão e Borges (2000), Wersig, na década de 70, já se definia a Ciência da Informação em dois planos: no primeiro indicava a similaridade de objetos de estudo e de proximidade com a Biblioteconomia, a Museologia, a Arquivística e a Educação; e, no segundo, "contemplava" uma ampla gama de disciplinas que se concentram no estudo dos processos de informação, como a Economia, a Ciência Política, as Tecnologias da Informação, a Sociologia e a Psicologia.

Mais recentemente Capurro (2003) apresenta três paradigmas para a Ciência da Informação: o paradigma físico, que privilegia a ideia de informação como "coisa" a ser transferida de um ponto a outro; o paradigma cognitivo, inspirado na filosofia de Popper e que enfatiza a informação como elemento alterador dos modelos mentais dos usuários; e o paradigma social, que atua na perspectiva de se entender a informação por parte de comunidades de usuários, resgatando a ideia de intersubjetividade para o entendimento da informação.

Apesar de suas especificidades, a evolução teórica da Biblioteconomia, da Arquivologia e da Museologia tem apontado para a superação das distinções disciplinares entre elas e a Ciência da Informação e o conceito de informação surgem como possíveis aglutinadores e potencializadores de seu desenvolvimento (ARAÚJO, 2011).

Portanto, é imprescindível identificar conceitos, teorias e métodos comuns à essas áreas, a partir da produção científica publicada e dos instrumentos pedagógicos existentes, de maneira a identificar a estrutura significante e elaborar um mapa conceitual terminológico capaz de referenciar o ensino e a pesquisa no domínio da Ciência da Informação.

\section{O referencial teórico}

Conceituar e dar nomes são atividades inerentes ao processo de pesquisa, pois a cada descoberta ou invento é necessário relacionar suas características em enunciados que, reunidos em uma definição, explicitam o seu significado sendo por fim designado por um termo.

Se com o advento da Revolução Industrial no século 17 teve início a necessidade de se delinear os elementos básicos de compreensão da terminologia, como conjunto de termos de uma área técnica ou científica e também como disciplina de natureza linguística que estuda 
esse conjunto (BARROS, 2004), a partir do século 20, a necessidade de normalização terminológica se impõe como consequência de duas características do desenvolvimento do conhecimento científico, a interdisciplinaridade das ciências e as suas micro especializações. A primeira necessita de uma padronização dos termos para garantir a comunicação entre os especialistas, seja no interior de uma mesma disciplina, seja entre disciplinas diferentes. Já a segunda, acentua a criação de neologismos, isto é, termos novos ou antigos com nova significação, como por exemplo, o termo vírus, originalmente da biologia que foi tomado por empréstimo pela informática (RONDEAU, 1984).

No final do século 20 Cabré (1995), em sua Teoria Comunicativa de Terminologia (TCT) define a terminologia enquanto disciplina que se ocupa de termos especializados, com diretrizes ou princípios que regem a compilação dos termos; e como produto gerado pela prática, isto é, o próprio conjunto de termos de uma área específica. Enquanto conjunto de termos de uma área específica, a terminologia possibilita a comunicação científica já que os especialistas de um domínio têm necessidade em padronizar a denominação de novos conceitos e novas descobertas e são os termos que cumprem a função de representar e transmitir o conhecimento no interior de um domínio.

Se dominar a terminologia de uma área torna possível dominar o conhecimento produzido naquela área, consequentemente, dominar a terminologia torna-se também ferramenta imprescindível no processo de aprendizagem de um saber-fazer, isto é, de um saber profissional. A divisão entre a língua geral e linguagens específicas, com suas respectivas terminologias, encontra-se na base da estrutura que nossa sociedade deu ao conhecimento e às profissões que representam (SAGER 1993). Portanto, ao se estabelecer o conjunto terminológico de um domínio e estruturá-lo a partir das relações entre termos facilita-se o processo de apropriação dos conceitos desse domínio e consequentemente dos conhecimentos aí produzidos.

Enquanto disciplina a terminologia estabelece regras e princípios a partir dos quais os termos devem ser coletados. Um termo designa um determinado objeto por meio da definição, que reúne propriedades e características que remetem a determinados contextos que são referendados nos discursos de especialidade.

O termo é definido pelos organismos internacionais de normalização como “designação, por meio de uma unidade linguística, de um conceito definida em uma linguagem de especialidade" (ISO, 1990, p.5). É reconhecido também como "unidade lexical 
especializada que tem como função primordial expressar o conhecimento de caráter científico, técnico e tecnológico e como missão paralela transferir o conhecimento veiculado pela comunicação humana" (KRIEGER, 2001, p.66).

Essas características do termo explicam o uso das terminologias dos domínios nas linguagens especializadas, pois a desejada precisão conceitual tornaria mais eficiente a comunicação entre especialistas de um dado domínio, promovendo a circulação do saber científico e técnico e fixando os seus conceitos. Atualmente, com a crescente interdisciplinaridade entre as ciências, torna-se quase impossível manter essa univocidade do conceito, pois se o conceito científico deve ser estável, paradigmático e universal, os significados linguísticos são variáveis conforme o contexto discursivo e pragmático.

Cabré (1993) defende que quando as palavras da língua comum adquirem significados específicos, pertinentes a determinado campo de saber científico ou técnico, ocorre o processo da terminologização. Neste processo cruzam-se as fronteiras dos universos discursivos dos conhecimentos especializados e as terminologias também passam a integrar o léxico geral dos falantes de uma língua. A delimitação entre o léxico geral e os léxicos especializados é afetada, abalando as proposições de que o conjunto das terminologias constitui subcomponentes do léxico geral. Dessa maneira, Cabré, através da TCT, justifica seu ponto de vista de que os termos não constituem um sistema independente das palavras, mas que junto a elas constituem o léxico do falante e que podem ser analisados de outras perspectivas, compartilhando com outros signos de sistemas não linguísticos o espaço da comunicação especializada.

Claudine Normand (apud KRIEGER, 2001) também corrobora a teoria de Cabré ao considerar que o léxico científico na comunicação comporta-se como qualquer outro léxico em que a difusão, os empréstimos, as analogias intervêm e são acompanhadas de mudanças de sentido, a sinonímia e a polissemia persistem ligadas à atividade científica, observando-se um trabalho constante de reformulação.

Krieger (2001) considera que o termo compreende tanto uma vertente conceitual expressando conhecimento e fundamentos dos saberes quanto uma vertente linguística, determinado sua naturalidade e integração aos sistemas linguísticos, além dos aspectos sociais que se agregam a uma de suas funcionalidades básicas: a de favorecer a transferência de conhecimento. Assinala assim, a importância de se registrar que as comunicações especializadas não estão isentas das marcas sóciohistóricas que afetam a construção do 
conhecimento, e que os elementos textuais e discursivos vão corroborar na determinação das unidades terminológicas.

Dessa maneira, os problemas de identificação dos termos não podem se restringir aos limites da frase, nem a um recorte paradigmático, mas se explicam à luz dos fenômenos da textualidade e da discursividade e, nesse sentido, dentro de um processo pragmático de comunicação.

Conforme Krieger (2001, p.81) "o termo é uma unidade linguístico-pragmática que integra os processos de comunicação humana e distingue-se das outras unidades léxicas apenas por uma peculiaridade, a de veicular conteúdos no campo das ciências, das técnicas e das tecnologias", sendo justamente essa característica que nos interessa na construção de um mapa conceitual e terminológico.

Assim, para elaborar um mapa conceitual e terminológico no domínio da Ciência da Informação, em que é necessário identificar os termos de três subdomínios que a constituem, a Biblioteconomia, a Arquivologia e a Museologia, consideramos a TCT de Cabré o referencial teórico mais adequado para nortear esse trabalho, mas sem deixar de observar as normas ISO 1087 Terminology work - vocabular e 704 Terminology work-principles and methods, as quais prescrevem recomendações sobre princípios e métodos do trabalho terminológico que incluem a coleta e a harmonização de conceitos e termos.

A norma ISO 1087 define cada um dos conceitos da Terminologia enquanto disciplina científica, já a norma ISO 704 estabelece cada uma das etapas do trabalho terminológico desde a coleta, organização e apresentação dos termos de um domínio como, por exemplo: identificar conceitos e as relações entre os conceitos; analisar e modelar sistemas de conceitos baseados na identificação dos conceitos e nas suas relações; estabelecer representações do sistema de conceitos através de diagramas; definir conceitos; atribuir designações (termos) para cada conceito em uma ou mais línguas; registrar e apresentar dados terminológicos em forma impressa ou media eletrônica (terminografia). 


\section{O referencial metodológico}

\section{a) Mapas conceituais e/ou Topic Maps}

Um instrumento para tornar visível, na forma de um gráfico, a aprendizagem das crianças; assim Joseph D. Novak idealizou o mapa conceitual. Esse gráfico ordenaria um grupo de proposições sobre um determinado assunto em forma de árvore, onde os conceitos seriam os nós e a ligação entre os nós demonstrariam os relacionamentos entre os conceitos conectados. A visualização do conhecimento na forma de um mapa demonstraria o processo de aprendizagem e ao fornecer uma grande quantidade de dados o mapa conceitual estimula a solução de problemas e possibilita a percepção de diferentes caminhos dentro de um mesmo conjunto. (FENDRICH; PEREIRA, 2006; ROVIRA, 2005).

Um mapa conceitual é uma rede cognitiva. Nesta rede os conceitos de um domínio são os nós e as relações entre eles são indicadas por laços. Essas relações são estabelecidas em função das semelhanças entre os nós, ou seja, conceitos (nós) com características semelhantes encontram-se reunidos na mesma categoria e por esse motivo estão unidos por um laço (relação entre conceitos).

De acordo com Moreiro Gonzalez et al.(2004), um mapa conceitual pode ser elaborado para auxiliar na aprendizagem, gerar ideias, desenhar estruturas complexas como os sites da web, para comunicar ideias complexas e até integrar o conhecimento novo ao antigo e seu processo de elaboração passa pelas seguintes etapas: seleção dos conceitos que serão representados no mapa, lista desses conceitos, agrupamento dos conceitos relacionados (categorização), ordenação dos conceitos em forma bidimensional ou tridimensional; estabelecimento de relações entre cada par de conceitos mediante etiquetas.

No início dos anos 90, os editores de livros eletrônicos reunidos no chamado Grupo de Davenport elaboram a norma ISO/IEC 13250 com o objetivo de armazenar e processar a informação a partir de um formato padronizado, com regras para a representação da informação também a partir da definição dos conceitos e das relações entre eles (ROVIRA, 2005). Essa norma formaliza o conceito Topic Map, o qual passa a ser considerado o "GPS do universo da informação" na medida em que se mostra uma solução para navegar e organizar os crescentes recursos de informação, publicações de todos os tipos, especialmente os sites da web, além de estabelecer uma ponte entre os campos do conhecimento e a gestão da informação (MOREIRO GONZALEZ et al., 2004). 
Se de um lado os mapas conceituais são elaborados a partir de uma preocupação pedagógica, na qual o objetivo é a aprendizagem a partir da representação gráfica do conhecimento, de outro os topic maps pretendem representar graficamente o conhecimento para facilitar o armazenamento, a recuperação e a troca de dados/informação. Rovira (2005) considera os dois objetivos como complementares visto que a aprendizagem, ou melhor, a aquisição do conhecimento depende tanto da sua representação quanto da possibilidade do seu armazenamento, recuperação e disseminação.

Os conceitos e as relações que podem ser estabelecidas entre estes conceitos são os elementos chaves de um mapa conceitual e também de um topic map, portanto é possível, como bem coloca Rovira (2005), utilizar a norma para topic map para modelar um mapa conceitual.

De acordo com Silva e Lima (2012) o topic map pode ser utilizado como um padrão que permite implementar os instrumentos para representação da informação e também descrever e navegar através de objetos informacionais em um sistema digital de modo contextualizado.

A norma do topic map, além de dar suporte à elaboração de um mapa conceitual referenciando o domínio de uma área do conhecimento para fins de aprendizagem, também permite ao mapa conceitual se transformar em uma representação de alto nível da informação indexada, facilitando a localização dos recursos informacionais (SILVA; LIMA, 2012).

A norma para topic map indica como componente essencial desta ferramenta o tópico, que representa uma pessoa, entidade ou assunto, o qual possui três características principais, sua denominação, suas ocorrências e suas associações. Cada tópico se define por sua denominação, por suas relações e pelo seu âmbito (escopo) (MOREIRO GONZALEZ et al, 2004).

Assim, podemos agregar à elaboração dos mapas conceituais os procedimentos terminológicos, presentes na TCT e nas normas ISO, os quais exigem uma definição acurada de cada conceito relacionado em uma terminologia de domínio. Dessa maneira, partindo de definições terminológicas é possível refinar e dar maior consistência a cada um dos chamados nós/tópicos (conceitos) do topic map/mapa conceitual, assim como às relações estabelecidas entre esses conceitos, sejam elas associativas, de equivalência ou hierárquicas. 


\section{b) Ontologias}

O termo ontologia surge na Filosofia, definido como o estudo do ser e de suas propriedades fundamentais. De acordo com a etimologia da palavra, ontos (ser) e logos (saber) entende-se ontologia no seu aspecto existencial: é um saber sobre aquilo que é fundamental, comum a todos os entes singulares; e no seu aspecto essencial: busca determinar as leis, estruturas ou causas do ser em si (FEITOSA, 2006). A pergunta que a ontologia pretende responder é: quais tipos de coisas existem ou podem existir no mundo, e quais são as relações que essas coisas podem ter umas com as outras.

A teoria ontológica pretende representar o conhecimento humano de maneira estruturada, partindo da essência de cada fenômeno ou objeto e estabelece suas relações com outras essências, isto é, investiga quais são as propriedades e ou características essenciais de maneira a representar objetos, conceitos ou outras entidades existentes em uma área de interesse, bem como as relações entre tais objetos, conceitos e entidades; estruturando o conhecimento através de categorias. No sentido filosófico nós podemos nos referir à Ontologia como um sistema particular de categorias a partir de uma determinada visão de mundo (GUARINO, 1998).

No âmbito da Ciência da Informação, o termo ontologia identifica-se com a definição dada a ele na Ciência da Computação, ou seja, uma ontologia denota as especificações dos conceitos relevantes para um assunto no domínio, incluindo suas propriedades e relações entre eles, e uma classificação hierárquica destes conceitos em categorias e subcategorias.

Se alguns autores da área da Ciência da Informação definem ontologia como um tesauro com relações mais elaboradas entre os termos, outros avaliam que as ontologias vão além da função de uma Linguagem Documentária, sendo considerada como um instrumento de Organização do Conhecimento, o que evidencia uma limitação ao conceituá-la como instrumento de controle terminológico. O objetivo do uso da ontologia na Ciência da Informação é diminuir as ambiguidades presentes na linguagem natural através do consenso terminológico, proporcionando semântica aos termos constantes nos índices dos mecanismos de busca, e assim melhorando a recuperação da informação, o compartilhamento, o reuso da informação e o controle dos termos que a constituem (SANTOS; CORREA; SILVEIRA, 2013).

De acordo com Marcondes e Campos (2008) uma ontologia define um vocabulário comum para uma comunidade que precisa compartilhar informação em um determinado domínio. 
Inclui definições de conceitos básicos no domínio e as relações entre estes de forma que sejam interpretáveis por máquina. Sob este ponto de vista, para Guarino (1998), uma ontologia se refere a um artefato de engenharia, constituído por um vocabulário específico usado para descrever certa realidade, mais um conjunto de pressupostos explícitos sobre o significado pretendido que são os conceitos e suas relações.

Ao se preocupar com as relações entre conceitos e com a sua estruturação para representar um domínio do conhecimento, a ontologia aproxima-se da terminologia e dos mapas conceituais e pode colaborar na construção do mapa conceitual e terminológico pretendido, pois especifica as categorias fundamentais da existência, isto é, classifica os conceitos e examina as distinções que sustentam cada fenômeno no mundo. Se considerarmos uma ontologia como um sistema de conceitos inter-relacionados, podemos dizer que estas contêm basicamente três componentes, quais sejam: um conjunto básico de conceitos e relações; uma forma de representação; um conjunto de assertivas (MARCONDES; CAMPOS, 2008).

Definir as regras que regulam a combinação entre os conceitos e suas relações, no momento da elaboração de uma ontologia, permite ao usuário identificar a melhor maneira de formular sua consulta e obter um resultado preciso para sua busca de informação (ALMEIDA; BAX, 2003).

Portanto, alguns princípios básicos devem ser seguidos para a estruturação de ontologias, os quais nos parecem válidos também para a elaboração de um mapa conceitual e terminológico. São eles: clareza e objetividade; completeza; coerência; maximização da extensão; comprometimento ontológico mínimo; princípio da distinção ontológica; diversificação de hierarquias; modularidade e padronização. Dessa maneira será possível: fornecer o significado dos conceitos a partir de definições objetivas que expressem todas as características de determinado conceito de maneira ampla, permitindo inferências que sejam consistentes com essas definições; incluir novos conceitos gerais ou especializados sem a necessidade de revisão das definições existentes; especificar cada conceito dentro do contexto específico; utilizar o critério da identidade para realizar a distinção entre as classes de conceitos; usar critérios de classificação, o que permite herdar propriedades a partir de diferentes pontos de vista; reduzir a distância semântica entre conceitos similares, os quais são agrupados e representados como subclasses de uma classe e devem ser definidos utilizando-se as mesmas propriedades, enquanto conceitos menos similares são representados mais apartados na hierarquia; e padronizar nomes o tanto quanto possível (GOMEZ-PEREZ, 1999 apud FEITOSA, 2006).

InCID: R. Ci. Inf. e Doc., Ribeirão Preto, v. 4, n. 1, p. 26-48, jan./jun. 2013. 
Feitosa (2006, p. 77) resume da seguinte maneira os vários conceitos e aplicações de uma teoria ontológica:

\begin{abstract}
uma ontologia define vários conceitos de um domínio do conhecimento, por meio de um vocabulário; uma aplicação faz uso dos objetos, por meio de axiomas e de regras lógicas; tais regras dizem como utilizar os conceitos referenciados, com vistas à solução de problemas em particular; há sempre uma estrutura que melhor representa o domínio do conhecimento, mas tal estrutura depende dos objetivos do sistema e, por isso, deve obedecer a certos princípios; existem níveis de formalismo a serem estabelecidos, os quais terão inferência determinante na efetividade do sistema; mas também se conformam aos objetivos do sistema.
\end{abstract}

Portanto, a partir dos procedimentos ontológicos e terminológicos é preciso empreender esforços de maneira a operacionalizar a elaboração de um mapa conceitual e terminológico que, não só represente o conhecimento de um domínio, mas, sobretudo, aumente a capacidade de recuperação da informação relevante diante da interdisciplinaridade das áreas e da diversidade do uso profissional. Além disso, espera-se que esse instrumento contribua para a apropriação do conhecimento através dos processos de cognição e decisão embasados nas relações de significação identificadas pelo sujeito que o utiliza.

\title{
O Mapa Conceitual e Terminológico em Ciência Informação
}

A elaboração de um mapa conceitual e terminológico se inicia a partir do estabelecimento de um perfil do domínio de conhecimento que se quer mapear. Para isso é necessário conhecer a base epistemológica do domínio, isto é, a maneira como se desenvolvem seus conceitos e teorias, seus objetos de pesquisa e os domínios correlatos.

Segundo Thellefsen (2004), para criar o perfil de conhecimento de um domínio devese em primeiro lugar considerar o conceito mais geral que tem influência nesse domínio, ou seja, o signo fundamental do domínio, a ideia central de um domínio, o conceito a partir do qual todos os demais são compreendidos. Portanto, identificar o signo fundamental de um domínio permite elaborar o perfil de conhecimento deste domínio e manter o projeto na trilha terminológica.

Considera-se neste trabalho que o conceito mais geral, ou signo fundamental da Ciência da Informação é a informação, pois este é o seu objeto de estudo como se observa nas definições a seguir, e sobre o qual, atualmente, convergem as pesquisas na Biblioteconomia e na Documentação, na Arquivologia e na Museologia.

InCID: R. Ci. Inf. e Doc., Ribeirão Preto, v. 4, n. 1, p. 26-48, jan./jun. 2013. 
Smit e Barreto (2002) consideram a Ciência da Informação, um campo de estudo, que se preocupa com os princípios e práticas da criação, organização e distribuição da informação, bem como com o estudo dos fluxos de informação, desde sua criação até a sua utilização, e sua transmissão ao receptor em uma variedade de formas e por meio de uma variedade de canais.

Cunha e Cavalcanti (2008, p.81) no "Dicionário de Biblioteconomia e Arquivologia" definem a Ciência da Informação como a disciplina que "investiga as propriedades e o comportamento da informação, as forças que governam o fluxo da informação e os meios para o seu processamento sem deixar de se preocupar com uma ótima acessibilidade e usabilidade".

Portanto, torna-se necessário definir o conceito de informação e suas categorias principais para realizar o agrupamento em categorias dos termos presentes no domínio da Ciência da Informação, utilizando-se as normas, princípios e critérios que norteiam a elaboração dos mapas conceituais, topic maps, ontologias e terminologias de maneira identificar e estabelecer as relações hierárquicas, associativas e de equivalência, a partir das características de cada um dos conceitos identificados como pertencentes ao domínio da Ciência da Informação, e que vão integrar o seu mapa conceitual e terminológico.

\section{A Informação}

Em uma sociedade globalizada, interdisciplinar e cada vez mais informatizada, a procura pela definição do que vem a ser informação é uma constante, e longe de se chegar a uma definição monorreferencial e global, o máximo que se pode almejar é definir informação a partir de contextos específicos. Assim, apresentamos a seguir as definições propostas de informação enquanto signo fundamental da Ciência da Informação.

Segundo Le Coadic (2004, p.4) “informação é um conhecimento inscrito (registrado) em forma escrita (impressa ou digital), oral ou audiovisual, em um suporte, o qual comporta um elemento de sentido", isto é, um significado que é transmitido a um ser consciente por meio de uma mensagem inscrita em um suporte espacial-temporal.

O Dicionário de Biblioteconomia e Arquivologia inicia o verbete informação definindo-a como o registro de um conhecimento, mas também coloca que ela pode ser 
descrita em termos do seu objeto de referência, seu significado e estrutura, arrolando os conceitos: assimilação da informação, medida da informação, necessidade de informação, processamento de informação, suporte da informação, teoria da informação e tratamento da informação (CUNHA; CAVALCANTI, 2008).

Robredo (2003, p.9) relaciona as características do que pode ser considerado como informação, ou seja,

aquilo que pode ser: registrada (codificada) de diversas formas; duplicada e reproduzida ad infinitum; transmitida por diversos meios; conservada e armazenada em suportes diversos; medida e quantificada; adicionada a outras informações; organizada, processada e reorganizada segundo diversos critérios e recuperada quando necessário segundo regras pré-estabelecidas.

O autor considera também que converter a informação em conhecimento é um ato individual, independe da tecnologia, para o qual é necessária a compreensão prévia dos códigos de representação de dados e dos conceitos, sejam eles transmitidos num processo de comunicação ou gravados num suporte material.

Segundo Le Coadic, nosso estado de conhecimento sobre determinado assunto, em determinado momento, é representado por uma estrutura de conceitos ligados por suas relações: nossa imagem de mundo, e quando constatamos uma deficiência ou anomalia desse estado de conhecimento tentamos obter uma informação que corrigirá essa anomalia e resultará um novo estado de conhecimento. Desta forma, infere que a informação é primeiramente mantida numa fonte e mais tarde alcança o entendimento do receptor (usuário) após passar por uma série de processos: codificação, passagem através de um canal e decodificação. O conhecimento é codificado e reduzido a informação, ao ser registrado ou transmitido em forma de símbolos, como, por exemplo, à escrita, Esta informação pode ser transformada em conhecimento pelos indivíduos que têm acesso ao código ou ao esquema de análise. Portanto, para poder ser utilizado por mais pessoas, sem limitações de tempo e espaço, supõe-se que o conhecimento tenha sido registrado e por isso mesmo transformado em informação (LE COADIC apud ROBREDO, 2003, p.15).

Segundo Smit (2000) a informação não registrada em algum tipo de suporte, isto é, o conhecimento, por mais importante que seja não é passível de uma socialização mais ampla, uma vez que seu consumo é condicionado pelas variáveis espaciais e temporais. A necessidade de estocar a informação e disponibilizá-la para uso levou ao surgimento das bibliotecas, museus e posteriormente os centros de documentação, os quais se caracterizam pela institucionalização da informação, isto é, pela garantia da sua socialização.

InCID: R. Ci. Inf. e Doc., Ribeirão Preto, v. 4, n. 1, p. 26-48, jan./jun. 2013. 
Para Latour (2000, p.22) “a informação não é um signo, e sim uma relação estabelecida entre dois lugares, onde o primeiro lugar é denominado de periferia e o segundo, denominado de centro, sendo que entre os dois circula uma forma, que para insistir em seu aspecto material é chamada por ele de inscrição". De acordo com este ponto de vista, informação, por exemplo, é o que os membros de uma expedição devem levar na volta, para que um centro possa fazer ideia de como é o lugar visitado. A informação permite justamente limitar-se a forma, sem ter o embaraço da matéria, por exemplo, levam-se os desenhos do papagaio e não o papagaio. Assim, a produção de informações é compreendida através das instituições que permitem o estabelecimento de relações de dominação entre o centro e a periferia através da sua representação.

Buckland (1991, p.351) distingue três tipos de informação em seus estudos: "a informação como processo, a informação como conhecimento e a informação como objeto". A informação como processo é o ato de informar, ou seja, alguém é informado de alguma coisa e o seu saber é modificado. A informação como conhecimento é usada para denotar o que é percebido na informação como processo, já o conhecimento comunicado concerne a um evento, assunto ou fato particular. A informação como objeto se refere a dados, documentos e objetos que são considerados informativos por terem a qualidade de conceder o conhecimento ou comunicar a informação. É na informação como objeto que o conhecimento foi registrado e pode ser classificado.

A informação como objeto, isto é, os dados (registros armazenados no computador); os documentos (livros, periódicos, microformas, documentos eletrônicos) e objetos potencialmente informativos (fósseis de dinossauros, amostras geológicas, artefatos indígenas) pode de ser reunida, selecionada, condensada, classificada, organizada e disponibilizada para o usuário através de procedimentos, ou seja, de representações, que descrevem o suporte físico da informação e a informação contida nestes suportes.

A informação como objeto depende do processamento para ser assimilada e ter a capacidade de gerar novos conhecimentos. É este processamento que vai transformá-la naquilo que Barreto (1994) denomina de estruturas significantes, Lara (1993) de representação documentária e Kobashi de informação documentária (1994).

Como vemos, a informação pode ser definida, no âmbito da Ciência da Informação, como um conjunto de dados capaz de propiciar uma ação de comunicação entre o estoque de conhecimentos, armazenados e o seu usuário, tornando possível a produção de novos 
conhecimentos a partir de sua socialização. Neste trabalho, consideramos informação como o conhecimento registrado em qualquer tipo de suporte que pode ser mapeada por termos, os quais denominam conceitos de um determinado domínio e são definidos pelas relações que estabelecem entre si. A apropriação desses conceitos permite a aquisição e disseminação do conhecimento no interior de um domínio, além de permitir a representação da informação em sistemas de recuperação de informação.

Outra etapa, para a elaboração de um mapa conceitual e terminológico, é a definição de suas categorias, isto é, a partir do signo fundamental identificar quais são os conceitos elementares, que agregam conceitos, relacionados a este signo fundamental, em classes, a partir de suas semelhanças e os excluem a partir de suas diferenças.

\section{A Categorização}

Na Filosofia a categorização ou classificação ontológica, organiza um conjunto de entidades em grupos, baseados em suas essências e possíveis relações (SHIRKY, 2011). Em seu Organón Aristóteles, já dividia o conhecimento em dez categorias que servem para classificar qualquer entidade, a saber: "Substância, Quantidade, Qualidade, Relação, Lugar, Tempo, Posição, Estado, Ação e Paixão” (2010, p. 41).

No âmbito da Biblioteconomia categorizar é classificar documentos em relação a um conjunto de categorias, ou seja, categorizar ou classificar é colocar um documento numa classe, dentro de uma estrutura, agrupando-os por suas características comuns de acordo com seus conteúdos. Conforme Aranalde (2009), as categorias são elementos intermediários entre os conceitos e a realidade cognoscível.

Ranganathan, bibliotecário indiano, em sua Colon Classification instituiu o conceito de faceta, onde qualquer assunto poderia ser analisado por um ponto de vista, isto é, cada assunto poderia ser categorizado de acordo com uma das seguintes facetas: Personalidade; Matéria; Energia; Tempo e Espaço. Segundo Barbosa (1972, p. 74), "na metade do século 20, o Classification Research Group (CRG) que contava com vários pesquisadores na área da classificação como Foskett, Coates, Vickery, Langridge, entre outros, deu continuidade aos estudos de Ranganathan". 
O tesauro surge na metade do século 20 como um instrumento de controle de assuntos que permite indexar e recuperar a informação registrada nos vários suportes documentários, pois se tratava de um sistema de palavras autorizadas com uma estrutura de referências cruzadas Apresentado tanto em ordem alfabética quanto em ordem hierárquica, o tesauro permite ao usuário encontrar o termo específico para a realização do processo de busca e ao mesmo tempo verificar as relações existentes entre o termo escolhido e os demais termos de um domínio.

O processo de categorização está presente na elaboração do tesauro, pois pressupõe arranjo, síntese, sistematização, agrupamento por critérios pré-determinados que são pontos de vista sobre a realidade, ocorre que para criar categorias é necessário que cada uma delas possa ser representada por um termo ou conjunto de termos que suportam o significado do conceito associado (PEIXOTO; BATISTA; CAPELO, [2003]; LARA, [200-] ). Assim, o problema é identificar o termo ou conjunto de termos cujo significado semântico possa definir o conceito de uma determinada categoria, pois muitas vezes o ponto de vista de quem elabora o tesauro se sobrepõe às necessidades dos usuários. Além disso, apesar das diretrizes e normas publicadas para padronizar a construção dos tesauros, como bem colocam Campos e Gomes (2006), as abordagens linguísticas que privilegiam a forma lexical e, portanto, variam de tesauro para tesauro, de norma para norma e de língua para língua, interferem no relacionamento entre os termos.

Com sua Teoria do Conceito, Dahlberg (1978) também nos traz subsídios para pensar o processo de categorização na elaboração de um mapa conceitual terminológico. Segundo a autora identificamos as categorias no momento da determinação do conceito quando inferimos as predicações verdadeiras, isto é, as características de um item de referência do domínio observado, e esta propriedade nos permite sistematizar o conhecimento deste domínio. Fazendo uma analogia com o corpo humano Dahlberg considera as categorias como o esqueleto do conhecimento, que pode se manter unido, pode se mover e pode-se manter flexível.

Para Shirky (2011), algumas características podem ser úteis quando se trata de categorizar um domínio a ser organizado: corpus pequeno; categorias formais; entidades estáveis; entidades restritas e limites claros. Segundo o autor, também não pode deixar de ser considerada a questão "quem são os participantes?" No âmbito desse trabalho consideram-se como público de um mapa conceitual e terminológico do domínio da Ciência da Informação, 
em primeiro lugar os seus pesquisadores, pois são os criadores dos conceitos desse domínio e, em segundo lugar, os docentes, estudantes e profissionais da área, os quais vão fazer uso desses conceitos, seja na transmissão do conhecimento, seja nas aplicações profissionais da área.

\section{Considerações Finais}

A dimensão aplicada da organização do conhecimento só é possível com o estabelecimento de estruturas que representem o conhecimento produzido e possibilitem a sua disseminação. Dito de outro modo, é necessário elaborar estruturas que representem a pesquisa e possibilitem o ensino no interior de determinado domínio, além de referenciar os processos de representação e recuperação da informação desse domínio, sejam eles no âmbito educacional ou profissional.

A análise do referencial teórico e metodológico apresentado permite inferir que a elaboração de um mapa conceitual e terminológico do domínio da Ciência da Informação considerando-se como signo fundamental do domínio o conceito de informação, envolve as seguintes etapas e respectivos referenciais teóricos metodológicos:

- Coleta de termos / Normas terminológicas e Teoria Comunicativa da Terminologia (TCT)

- Categorização dos conceitos / Teoria do Conceito

- Estruturação do mapa conceitual terminológico / critérios para apresentação dos topic maps e das ontologias.

Assim, com objetivo de proceder a uma aplicação prática desses referenciais teóricos e metodológicas deverá ser realizada uma coleta dos termos, tanto nas estruturas curriculares vigentes nos cursos de graduação e pós-graduação em Biblioteconomia e Documentação, Arquivologia e Museologia, quanto na produção científica publicada nas revistas científicas e nos trabalhos apresentados nos eventos científicos e profissionais. Essa coleta se dará sob a orientação das regras estabelecidas nas normas ISO 704 e 1087.

A partir da coleta de termos, os mesmos deverão ser definidos, de modo a elencar as características de cada um, o que permitirá a identificação dos conceitos que deverão ser objeto de categorização. Essa categorização deverá ser feita a partir dos princípios básicos para a estruturação de topic maps e ontologias, especificamente aqueles que podem ser 
aplicados à estruturação de um mapa conceitual e terminológico, a saber: especificação de cada conceito no interior de um contexto específico; a utilização do critério de identidade para distinguir entre as classes de conceitos; a utilização de critérios de classificação que permite herdar propriedades a partir de diferentes pontos de vista; a redução da distância semântica entre conceitos similares, os quais são agrupados em subclasses de uma classe e devem ser definidos utilizando-se as mesmas propriedades, enquanto conceitos menos similares são representados mais isoladamente na hierarquia e a indicação dos tipos de relações entre os conceitos, a partir das propriedades de cada um, sejam elas hierárquicas, de equivalência ou associativas.

As demais etapas do trabalho preveem a análise e a modelagem do sistema conceitual baseado na definição de cada conceito e suas características essenciais. São essas características essenciais que permitirão o estabelecimento de relações semânticas entre os termos do domínio que vem sendo objeto de pesquisa e ensino, e serão utilizados para representar e recuperar a informação e elaborar efetivamente um mapa conceitual e terminológico da Ciência da Informação.

\section{Referências}

ALMEIDA, M. B.; BAX, M. P. Uma visão geral sobre ontologias: pesquisa sobre definições, tipos, aplicações, métodos de avaliação e de construção. Ciência da Informação, Brasília, v. 32, n. 3, p. 7-20, set./dez. 2003.

ARANALDE, M. M. Reflexões sobre os sistemas categoriais de Aristóteles, Kant e Ranganathan. Ciência da Informação, Brasília, v. 38, n. 1, p. 86-108, jan./abr. 2009.

ARAÚJO, C. A. A. Ciência da Informação como campo integrador para as áreas de Biblioteconomia, Arquivologia e Museologia. Informação \& Informação, Lodrina, v.15, n.1, p. 173-189, jan./jun. 2010.

ARAÚJO, C. A. A. Condições teóricas para a integração epistemológica da Arquivologia, Biblioteconomia e Museologia na Ciência da Informação. InCID: R. Ci. Inf. Doc. Ribeirão Preto, v.2, n.2, p.19-41, jul./dez. 2011

ARISTÓTELES. Órganon. 2.ed. São Paulo: EDIPRO, 2010.

BARITÉ ROQUETA, M. G.. La definición de conceptos y su impacto sobre la representación del conocimiento com fines documentales. In: CONGRESO ISKO, 5., 2001, Madrid. Actas, Madrid: ISKO, 2001. p.88-101. 
BARBOSA, A. P. Classificações facetadas. Ciência da Informação. v. 1, n. 2, p.73-81, 1972.

BARRETO, A. A. A questão da informação. São Paulo em Perspectiva, v.8, n.4, p.3-8, 1994.

BARROS, L. A. Curso básico de terminologia. São Paulo: EDUSP, 2004.

BORKO, H. Information science: what is it? American Documentation, v. 19, n. 1, p. 3-5, jan. 1968. Disponível em: <http://pt.scribd.com/doc/533107/Borko-H-v-19-n-1-p-35-1968>. Acesso em: 02 fev. 2013.

BUCKLAND, M. Information as thing. Journal of the American Society for Infomation Science, v. 42, n. 5, p. 351-360, 1991.

BUSH, V. As we may think? The Atlantic Monthly, 01 jul. 1945. Disponível em: $<$ http://www.theatlantic.com/magazine/archive/1945/07/as-we-may-think/303881/>. Acesso em: 10 fev. 2013.

CABRÉ, M. T. La terminologia: teoria, metodologia e aplicaciones. Barcelona: Antártida/Empúries, 1993.

CABRÉ, M. T. La terminologia hoy: concepciones, tendências y aplicaciones. Ciência da Informação, Brasília, v. 24, n. 3, p. 289-298, set./dez. 1995.

CAMPOS, M. L. A.; GOMES, H. E. Metodologia de elaboração de tesauro conceitual: a categorização como princípio norteador. Perspectivas em Ciência da Informação, Belo Horizonte, v. 11 n. 3, p. 348-359, set./dez. 2006.

CAPURRO, R. Epistemologia e ciência da informação. In: ENCONTRO NACIONAL DE PESQUISA EM CIÊNCIA DA INFORMAÇÃO, 5., 2003, Belo Horizonte. Anais... Belo Horizonte: ANCIB, 2003.

CUNHA, M. B.; CAVALCANTI, C. R. O. Dicionário de biblioteconomia e arquivologia. Brasília: Briquet de Lemos, 2008.

DAHLBERG, I. Ontical structures and universal classification. Bangalore: Sarada Ranganthan Endowment, 1978.

FENDRICH, L. J.; PEREIRA, L. Ensinar e aprender no ensino superior através de mapas conceituais In: SIMPEP, 8., 2006, Bauru. Anais... Bauru, 2006.

FEITOSA, A. Organização da informação na web: das tags à web semântica. Brasília: Thesaurus, 2006.

GALVÃO, M.C. B.; BORGES, P. C. R. Ciência da informação: ciência recursiva no contexto da sociedade da informação. Ciência da Informação, Brasília, v.29, n.3, p.40-49, set./dec. 2000 .

GUARINO, N. Formal ontology in information systems. In: FOIS'98, 1998, Trento. Proceedings... Amsterdam, IOS Press, 1998. p. 3-15. 
ISO_Principles and methods of terminology: ISO 704. Geneve: ISO, 1987.

ISO. Terminologie - vocabulaire: ISO 1087. Geneve: ISO, 1990.

KOBASHI, N. Y. A elaboração de informações documentárias: em busca de uma metodologia. 1994. 195 f. Tese (Doutorado em Comunicação) - Escola de Comunicações e Artes, Universidade de São Paulo, São Paulo, 1994.

KRIEGER, M. G.; MACIEL, A. M. B. (Org.). Temas de terminologia. Porto Alegre: Ed. UFRGS; São Paulo: Humanitas/USP, 2001.

LATOUR, B. Redes que a razão desconhece: laboratórios, bibliotecas, coleções. In: BARATIN, M.; JACOB, C. O poder das bibliotecas: a memória dos livros no ocidente. Rio de Janeiro: Ed. UFRJ, 2000. p. 21-44.

LARA, M. L. G. Conceito de organização. São Paulo, [200-]

LARA, M. L. G. Representação documentária: em jogo a significação. 1993. 133 f. Dissertação (Mestrado em Comunicação) - Escola de Comunicações e Artes, Universidade de São Paulo, São Paulo, 1993.

LE COADIC, Y. F. A ciência da informação. 2. ed., rev. atual. Brasília: Briquet de Lemos, 2004.

MARCONDES, C. H.; CAMPOS, M. L. A. Ontologia e web semântica: o espaço da pesquisa em Ciência da Informação. PontodeAcesso, Salvador, v. 2, n. 1, p. 107-136, jun./jul. 2008. Disponível em <www.pontodeacesso.ici.ufba.br>. Acesso em: 12 mar. 2013.

MOREIRO GONZALEZ, J. et al. De los tesauros a los topic maps: nuevo estandar para la representación y la organización de la información. Encontros Bibli: Revista Eletrônica de Biblioteconomia e Ciência da Informação, Florianópolis, n. 18, p. 1-19, $2^{\circ}$ sem. 2004.

PEIXOTO, M. D. F.; BATISTA, M. G. T. R. H; CAPELO, M. J. T. S. P. Categorização de textos. Covilhã: Departamento de Informática da Universidade da Beira Interior, [2003]. Disponível em: <www.di.ubi.pt/ api/text_categorization.pdf>. Acesso em: 20 fev. 2013.

POMBO, O. Dispersão e unidade: para uma poética da simpatia. In: LARA, M. L. G.; SMIT, J. W. (Orgs.) Temas de pesquisa em Ciência da Informação no Brasil. São Paulo: ECA/USP, 2010. p. 29-46 Disponível em: <http://www.pos.eca.usp.br/index.php?q=ptbr/ciencia_da_informacao/publicacoes>. Acesso em: 16 maio 2013.

ROBREDO, J. Da ciência da informação revisitada aos sistemas humanos de informação. Brasília: Thesaurus; SSRR Informações, 2003.

ROVIRA, C. DigiDocMap conceptual maps editor and Topic Maps norms. Hipertext.net, n. 3, 2005. Disponível em: <http://www.hipertext.net>. Acesso em: 31 jan. 2011.

RONDEAU, G. Introduction à la terminologie. Chicoutimi: Gaetan Morin, 1984. 
SAGER, J. La terminologia, puente entre varios mundos. In: CABRÉ, M.T. La terminologia: teoria, metodologia, aplicaciones. Barcelona: Antártida: Empuries, 1993. p. 11-17.

SANTOS, M. T.; CORREA, R. F.; SILVEIRA, M. A. A. Estudos brasileiros sobre ontologia na Ciência da Informação. DataGramaZero - Revista de Informação, v. 14, n. 1, fev. 2013.

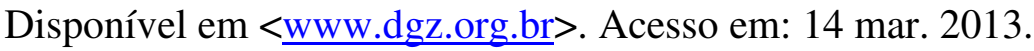

SHIRKY, C. Ontology is overrated: categories, links, and tags. 2011. Disponível em: <http://www.shirky.com/wrintings/ontologyover>. Acesso em: 25 fev. 2013.

SILVA, A. M. Arquivística, Biblioteconomia e Museologia: do empirismo patrimonialista ao paradigma emergente da ciência da informação. In: INTEGRAR - CONGRESSO INTERNACIONAL DE ARQUIVOS, BIBLIOTECAS, CENTROS DE DOCUMENTACÃO E MUSEUS, 1., 2002, São Paulo. Anais... São Paulo: Imprensa Oficial do Estado, 2002, p. 573-607.

SILVA, G. B. S.; LIMA, G. A. B. O. Using topic maps in establishing compatibility of semantically structured hipertexto contentes. Knowledge Organization, v. 39, n. 6, p. 432 445, 2012.

SMIT, J. W. Informação. In: LIMA, Y. D.; SMIT, J. W. (Org.). Organização de arquivos. São Paulo: IEB/ECA, 2000. p.19-31.

SMIT, J. Arquivologia, biblioteconomia e museologia: o que agrega estas atividades profissionais e o que as separa? Revista Brasileira de Biblioteconomia e Documentação, São Paulo, Nova Série, v. 1, n. 2, p. 27-36, fev. 2002.

SMIT, J. W.; BARRETO, A. A. ciência da informação: base conceitual para a formação do profissional. In: VALENTIM, M. L. P. (Org.). Formação do profissional da informação. São Paulo: Polis, 2002. p. 9-23.

THELLEFSEN, T. Knowledge profile: the basis for knowledge organization. Library Trends, v. 52, n. 3, p. 507-514, winter 2004. 